\title{
Development and Characterization of an Enzymatic Method for the Rapid Determi- nation of Gamma Hydroxybutyric Acid
}

\author{
Michel A. Sciotti ${ }^{\star a}$, Lara Hasan ${ }^{\mathrm{b}}$, André Scholer ${ }^{\mathrm{c}}$, Thomas M. Jermann ${ }^{\mathrm{b}}$, Jakob M. Weber ${ }^{\mathrm{b}}$, and \\ Daniel Gygax
}

\begin{abstract}
Gamma hydroxybutyric acid (GHB) is a regulated therapeutic drug, which naturally occurs in mammalian brain tissues as an intermediate of the GABA (gamma aminobutyric acid) neurotransmitter metabolism. The increasing misuse of GHB as a narcotic or abusing drug in recent years calls for the development of a simple and rapid screening method as an alternative to the currently available, technically demanding diagnostic methods. We have developed a rapid enzymatic assay based on the GHB dehydrogenase of Ralstonia eutropha. The enzyme is expressed as a recombinant protein in Escherichia coli and characterized in terms of reaction mechanism and kinetic parameters for the catalysis of conversion of GHB into succinic semialdehyde (SSA). The concomitant NADH production enables spectrophotometric monitoring of the reaction and the quantification of GHB in physiological fluids depending on initial velocities. We have tested a panel of twelve serum and urine samples containing GHB concentrations from 0.0 to $2.1 \mathrm{mmol} / \mathrm{L}$. GHB dehydrogenase activity obeys a non classical bi bi ping pong mechanism exhibiting substrate inhibition by NAD+. With an optimal $\mathrm{NAD}^{+}$concentration of $3.7 \mathrm{mmol} / \mathrm{L}$ in the reaction, the enzyme yields a $\mathrm{K}_{\mathrm{M}}$ of $1.0 \mathrm{mmol} / \mathrm{L}$ for $\mathrm{GHB}$ and a $V_{\max }$ of $3.37 \mathrm{mmol} / \mathrm{min} / \mathrm{mg}$. The assay shows a linear standard curve from 0.1 to at least $1 \mathrm{mmol} / \mathrm{L}$ of GHB. Spiking experiments result in mean recoveries of $92 \%$ for urine and $114 \%$ for serum, respectively. The comparison to an ion chromatographic reference method exhibits a mean difference of $10 \%$ divergence from the target values in urine and $9 \%$ in serum, respectively.
\end{abstract}

Keywords: Enzymatic assay · Gamma hydroxybutyric acid · GHB · GHB dehydrogenase - Reaction mechanism

\section{Introduction}

Despite perpetual interest and investigations, the precise physiology of GHB action is yet to be described. It has been proposed that the behavioral effects of GHB, as an analogue of GABA (gamma aminobutyric acid), are mediated by $\mathrm{GABA}_{\mathrm{B}}$ receptors. ${ }^{[1-3]}$ GHB uptake consolidates sleep and is used in treatment of narcolepsy or as accompanying palliative in alcohol- or drug-withdrawal therapy. $.4,5]$

In the recent decades, GHB, initially known only as an esoteric and controver-

\footnotetext{
${ }^{*}$ Correspondence: Dr. M.-A. Sciotti ${ }^{\mathrm{a}}$

Tel.: +41614674776

Fax: +41614674784

E-mail: michelangelo.sciotti@fhnw.ch

aHochschule für Life Sciences

Fachhochschule Nordwestschweiz

Gründenstrasse 40

$\mathrm{CH}-4132$ Muttenz

'Bühlmann Laboratories AG

Baselstrasse 55

$\mathrm{CH}-4124$ Schönenbuch

'Labormedizin

Universitätsspital Basel

$\mathrm{CH}-4031$ Basel
}

sial body building or fat burning drug, has taken on an increasing importance in the landscape of recreational drugs. ${ }^{[6,7]}$ The concern about misuse of the substance has been strengthened by media focus on the increased number of drug-facilitated assaults involving GHB. ${ }^{[8]}$

GHB intake in doses from 1 to $2.5 \mathrm{mg} /$ $\mathrm{kg}$ generally has a stimulating and euphoric effect that can be associated with sensations of relaxation and increased perception. An intake of GHB in doses over 10 $\mathrm{mg} / \mathrm{kg}$ may induce sleepiness, dizziness, confusion, aggressiveness, loss of memory, respiratory distress, seizures, and ataxia and may lead to coma or even death. ${ }^{[9,10]}$ The severity of the symptoms is aggravated through concomitant consumption of GHB with alcohol and other drugs. Repeated GHB consumption rapidly leads to strong dependence. $[11,12]$

Exogenous GHB uptake generates a GHB concentration peak in plasma after 20 to $45 \mathrm{~min}$. The half-life in plasma is estimated to be around $30 \mathrm{~min}$. GHB was detectable in urine collected up to $12 \mathrm{~h}$ after ingestion for an initial single dose of $25 \mathrm{mg} / \mathrm{kg} .{ }^{\left[{ }^{13]}\right.}$ Higher uptakes did not prolong the detection window. ${ }^{[14]} \mathrm{GHB}$ levels in collected samples stored frozen at -20 ${ }^{\circ} \mathrm{C}$ or lower should be stable. Prolonged storage of urine samples refrigerated at 5
${ }^{\circ} \mathrm{C}$ for up to 6 months led to a substantial increase of the initial GHB concentration over time. ${ }^{[15]}$

Two major analytical applications have been subject to recent developments, both promoted by the increase in GHB abuse: detection of GHB in body fluids and detection of the substance in food or beverages. Both approaches generally rely on gas chromatography methods (GC-MS) and have been proposed for blood, urine, saliva, animal tissues, food and beverages. ${ }^{[16-20]}$ Alternative approaches are rare. A rapid colorimetric chemical test has been proposed for qualitative detection of GHB in urine. ${ }^{[21]} \mathrm{A}$ dipstick assay based on a colorimetric enzyme reaction has been developed. It has been shown to detect GHB quantitatively in alcoholic beverages. ${ }^{[22]}$ The enzyme involved in the dipstick assay detection is the GHB dehydrogenase (GHBDH, E.C. 1.1.1.61) of Ralstonia eutropha. In this application, it catalyses the oxidization of GHB into succinic semialdehyde (SSA) associated with $\mathrm{NAD}^{+}$reduction.

In this study, we have synthesized, expressed and purified a recombinant GHB dehydrogenase based on the nucleotide sequence of the $g b d$ gene from Ralstonia eutropha. The reaction mechanism and kinetic properties of this newly synthesized 
GBHDH are characterized comprehensively. We also propose an enzymatic assay for the automated determination of GHB in blood and urine.

\section{Material and Methods}

\section{Patients, Specimens, and Materials}

Blood samples from anonymous, apparently healthy donors were obtained from the Blood Transfusion Centre Basel of the Swiss Red Cross. Control urine was collected from apparently healthy individuals among local population. The University Hospital of Basel, Switzerland, provided us with three serum and urine samples each from overdosed patients.

Unless otherwise indicated all reagents were obtained from Sigma-Aldrich (Buchs, Switzerland).

\section{Production of Recombinant GHB Dehydrogenase in E. coli}

The coding frame of Ralstonia eutropha gbd gene was generated according to the reference sequence UniProtKB/ TrEMBL:Q59104 by DNA synthesis (Genscript, USA) and amplified by PCR with Taq DNA polymerase (Invitrogen, USA) and primers $5^{\prime}$-atg gcg ttt atc tac tat c-3' and 5' -cta cat gga ctg ctc aag c-3'. The amplification product was directly ligated into the expression vector pQE-30 UA (Invitrogen, USA) according to the manufacturer's recommendations. The construction was propagated and expressed as a hexahistidinylated fusion product in Escherichia coli M15. The enzyme was purified from cell extract by his-tag IMAC affinity chromatography followed by ion exchange chromatography and dialyzed into $30 \mathrm{mM}$ 4-morpholinepropanesulfonic acid (MOPS) pH 7.4, $50 \mathrm{mM} \mathrm{NaCl}$. The homogeneity and integrity of the purified enzyme was confirmed by SDS-PAGE (Fig. 1). The SDS-PAGE was performed according to the Lämmli protocol using a 6-20\% gradient gel. ${ }^{[23]}$ The protein concentration was estimated by the method of Bradford and spectrophotometric measurement at $480 \mathrm{~nm} .{ }^{[24]}$

\section{Kinetic Enzyme Assays}

Instrumentation included the Cobas Mira Plus automated chemistry analyzer (Roche, Switzerland) and Infinite M200 UV spectrophometric plate reader, Model 160U (Tecan, Switzerland).

\section{Characterization of GHB Dehydro- genase Activity}

GHBDH activity means the enzyme catalyzed $\mathrm{NAD}(\mathrm{P})^{+}$dependent conversion of GHB into SSA. For the NAD $(\mathrm{P}) \mathrm{H}$ dependent conversion of SSA into GHB, the expression 'reverse reaction' is used.

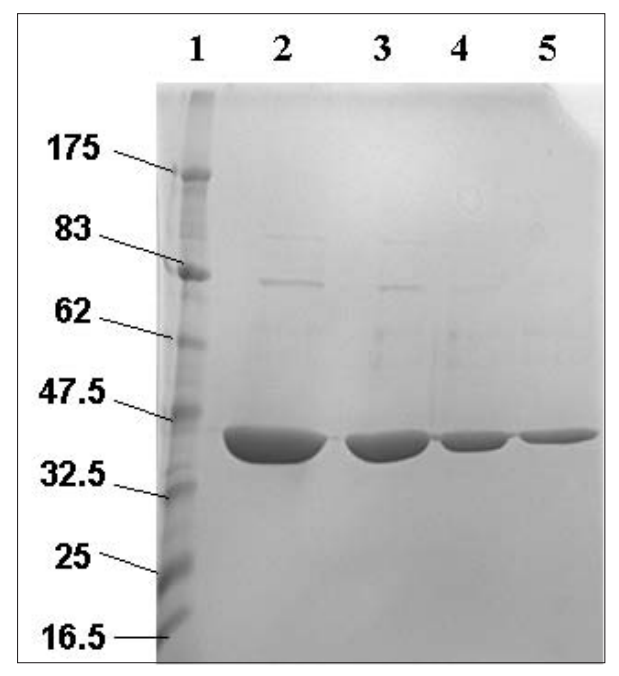

Fig. 1. The identity, purity and homogeneity of the GHBDH enzyme were assessed by SDSPAGE. A Coomassie Blue stain of the SDSPAGE is shown. Lane 1: $15 \mu \mathrm{L}$ of prestained broad range protein size marker (New England Biolabs, Frankfurt, Germany); lanes 2-5: 20 $\mu \mathrm{L}$ containing $20,10,4$ and $1 \mu \mathrm{g}$, respectively, of IMAC-purified His-tagged GHBDH fusion protein of a size of approximately $43 \mathrm{kDa}$. Calculated size deduced from the amino acid sequence is $42.7 \mathrm{kDa}$.

GHB concentrations are given in $\mathrm{mmol} / \mathrm{L}$ or $\mu \mathrm{mol} / \mathrm{L}$ ( $1 \mathrm{mmol} / \mathrm{L} \mathrm{GHB}$ corresponds to $105 \mathrm{mg} / \mathrm{L}$ of its free acid).

GHB dehydrogenase activity was measured by monitoring the rate of formation of NADH at $340 \mathrm{~nm}$. The reaction was performed in $100 \mu \mathrm{L}$ of $270 \mathrm{mmol} / \mathrm{L} 2$-amino2-methanol-1-propanediol (AMPD) buffer $\mathrm{pH} 10$ in the presence of 0.16 to $40 \mathrm{mmol} / \mathrm{L}$ $\mathrm{NAD}^{+}$and 0.31 to $20 \mathrm{mmol} / \mathrm{L} \mathrm{GHB}$. The specific reaction was initiated by adding $10 \mu \mathrm{L}$ AMPD buffer containing $2 \mu \mathrm{g}$ GHBDH enzyme. Measurements started after a delay of $60 \mathrm{sec}$ and were repeated in intervals of $60 \mathrm{sec}$.

Specific activity is expressed in $\mathrm{mmol} /$ $\mathrm{min} / \mathrm{mg}$ and was calculated using the molar extinction coefficient of NADH $\left(\varepsilon_{34}\right.$ $\left.=6.22 \mathrm{mmol}^{-1} \mathrm{~cm}^{-1}\right)$. Alternatively for product inhibition studies, the activity of GHB dehydrogenase was measured under the same conditions as above with the addition of 2 or $10 \mathrm{mmol} / \mathrm{L} \mathrm{SSA}$ and 0.125 to $1 \mathrm{mmol} / \mathrm{L} \mathrm{NADH}$, respectively.

\section{Data Processing}

Data plot processings were performed with GraphPad Prism 5 (GraphPad Software Inc., USA). Data were evaluated with different algorithms for the best fit. In all following algorithms, $\mathrm{V}$ corresponds to initial velocity and $\mathrm{V}_{\max }$ to the maximal initial velocity.

Data of GHBDH activity with varying $\mathrm{NAD}^{+}$concentrations at given GHB concentrations were fitted according to the substrate inhibition model approxi- mated by the algorithm $\mathrm{V}=\mathrm{V}_{\text {max }} \cdot\left[\mathrm{S}^{\prime}\right] /$ $\left(\mathrm{K}_{\mathrm{M}(\mathrm{NAD}+)}+\left[\mathrm{S}^{\prime}\right] \cdot\left(1+\left[\mathrm{S}^{\prime}\right] / \mathrm{K}_{\mathrm{i}(\mathrm{NAD}+)}\right)\right)$, where $\left[\mathrm{S}^{\prime}\right]$ corresponds to the NAD ${ }^{+}$start concentration and $\mathrm{K}_{\mathrm{M}(\mathrm{NAD}+)}$ and $\mathrm{K}_{\mathrm{i}(\mathrm{NAD}+)}$ to constants given in the same unit as [ $\left.\mathrm{S}^{\prime}\right]$.

Data plotted as a function of GHB concentration at low $\mathrm{NAD}^{+}$fixed concentrations were fitted according to the Michaelis-Menten algorithm $\mathrm{V}=\mathrm{V}_{\text {max }} \cdot[\mathrm{S}] /$ $\left(\mathrm{K}_{\mathrm{M}(\mathrm{GHB})}+[\mathrm{S}]\right)$, where $[\mathrm{S}]$ corresponds to $\mathrm{GHB}$ start concentration and $\mathrm{K}_{\mathrm{M}(\mathrm{GHB})}$ to a constant given in the same unit as [S]. Alternatively, these data were plotted as a function of $\mathrm{NAD}^{+}$and fitted according to the Michaelis-Menten algorithm $\mathrm{V}=$ $\mathrm{V}_{\max } \cdot\left[\mathrm{S}^{\prime}\right] /\left(\mathrm{K}_{\mathrm{M}(\mathrm{NAD}+)}+\left[\mathrm{S}^{\prime}\right]\right)$, where $\left[\mathrm{S}^{\prime}\right]$ corresponds to $\mathrm{NAD}^{+}$start concentration and $\mathrm{K}_{\mathrm{M}(\mathrm{NAD}+)}$ to a constant given in the same unit as [S'].

Data plotted as a function of GHB concentration at high $\mathrm{NAD}^{+}$fixed concentrations were fitted according to the competitive inhibition algorithm $\mathrm{V}=\mathrm{V}_{\max } \cdot[\mathrm{S}] /$ $\left(\mathrm{K}_{\mathrm{M}(\mathrm{GHB})}\left(1+\left[\mathrm{S}^{\prime}\right] / \mathrm{K}_{\mathrm{i}(\mathrm{NAD}+)}\right)+[\mathrm{S}]\right), \quad$ where [S] and [S'], respectively, correspond to GHB and $\mathrm{NAD}^{+}$initial concentrations and $\mathrm{K}_{\mathrm{M}(\mathrm{GHB})}$ and $\mathrm{K}_{\mathrm{i}(\mathrm{NAD+})}$, respectively, to constants given in same unit as [S] and [S'].

GHBDH activity in the presence of SSA yielded data fitting with the competitive inhibition model approximated by the algorithm $\mathrm{V}=\mathrm{V}_{\text {max }} \cdot[\mathrm{S}] /\left(\mathrm{K}_{\mathrm{M}(\mathrm{GHB})}(1+[\mathrm{I}] /\right.$ $\left.\left.\mathrm{K}_{\mathrm{i}(\mathrm{SSA})}\right)+[\mathrm{S}]\right)$, where $[\mathrm{S}]$ and $[\mathrm{I}]$, respectively, correspond to GHB and SSA initial concentrations and $\mathrm{K}_{\mathrm{M}(\mathrm{GHB})}$ and $\mathrm{K}_{\mathrm{i}(\mathrm{SSA})}$, respectively, to constants respectively given in same unit as [S] and [I].

\section{Spiking Recovery Assay}

The reaction was performed in $250 \mu \mathrm{L}$ final volume of $270 \mathrm{mmol} / \mathrm{L}$ AMPD buffer $\mathrm{pH} 10$, containing oxaloacetate, EDTA and preservatives, in the presence of $2 \mathrm{mmol} / \mathrm{L}$ $\mathrm{NAD}^{+}$and $10 \%(\mathrm{v} / \mathrm{v})$ of urine or serum from healthy individuals spiked with 100 , 500 or $800 \mu \mathrm{mol} / \mathrm{L}$ GHB. The reaction was initiated by adding $35 \mu \mathrm{L}$ AMPD buffer containing $5 \mu \mathrm{g}$ GHBDH and the NADH formation rate was monitored at $340 \mathrm{~nm}$ on a Roche Cobas Mira Plus clinical chemical analyzer. Measurements occurred in seven intervals of 25 seconds each. The gain in absorbance $(\Delta \mathrm{A})$ over 175 seconds was converted into concentration units by intersecting the absorbance units (AU) with a calibration curve resulting from measurements of $0,100,250,500$ and $1000 \mu \mathrm{mol} / \mathrm{L}$ GHB in deionized water (see Fig. 5 in Results section).

\section{Method Comparison}

The GHBDH dependent enzymatic assay was performed following the same protocol as for the spiking recovery experiments, except that no exogenous GHB was added and the urine or serum samples originated from overdosed patients. 
The reference method was an ion chromatographic assay established at the Clinical Laboratory of the University Hospital of Basel, Switzerland, and was performed with model 761 Compact IC chromatograph (Metrohm, Switzerland). ${ }^{[25,26]}$ Briefly, $20 \mu \mathrm{L}$ of extracted serum or urine was applied on a Metrosep Anion Dual 2 column (Metrohm, Switzerland) at a flow rate of $1 \mathrm{~mL} / \mathrm{min}$ and eluted with $0.2 \mathrm{mmol} / \mathrm{L}$ of aqueous heptafluorobutyric acid. The GHB concentration was deduced from the conductivity. This method was originally validated by comparing the results with a GC-MS reference method. $[25,26]$

\section{Results}

\section{Optimization of $\mathrm{pH}$}

The $\mathrm{pH}$ dependence of the GHBDH activity was examined from $\mathrm{pH} 6$ to 10 (Fig. 2). Assays performed either in 100 $\mathrm{mM}$ Tris- $\mathrm{HCl}$ or $100 \mathrm{mM}$ phosphate, 150 $\mathrm{mM} \mathrm{NaCl}$ (PBS) yielded very similar results. Only activities in Tris- $\mathrm{HCl}$ are shown in Fig. 2. Highest activities were observed between $\mathrm{pH} 9.5$ and 10. Activity was found to be optimal in $270 \mathrm{mM}$ AMPD pH 10.0 and yielded at least 50\% higher GHBDH activity than with Tris$\mathrm{HCl}$ (data not shown).

\section{Dependence of GHBDH Activity on Substrates GHB and NAD+}

Initial velocities presented in this work are calculated over the early linear phase of the reaction (min 1 to 11 ), excluding inhibition by substrate shortage or product accumulation.

GHBDH activity depends on both GHB and $\mathrm{NAD}^{+}$concentrations. Increasing $\mathrm{NAD}^{+}$concentration promoted the reaction. The gain in activity was observed up to $5 \mathrm{mmol} / \mathrm{L} \mathrm{NAD}^{+}$, independently of the GHB concentration. This gain in activity resulted from a concomitant increase in $\mathrm{V}_{\max }$ and $\mathrm{K}_{\mathrm{M}}$ and constant $\mathrm{K}_{\mathrm{M}} / \mathrm{V}_{\text {max }}$ slope.

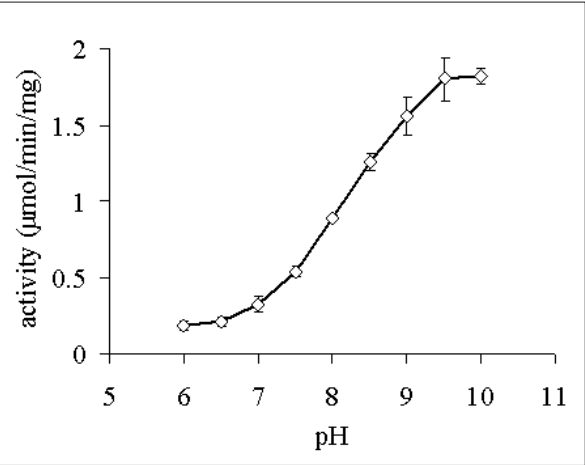

Fig. 2. GHBDH activity dependant on $\mathrm{pH}$. The reaction was performed in $100 \mathrm{mM}$ Tris- $\mathrm{HCl}$ in the presence of $2 \mu \mathrm{g} \mathrm{GHBDH}, 10 \mathrm{mmol} / \mathrm{L} \mathrm{GHB}$ and $1 \mathrm{mmol} / \mathrm{L} \mathrm{NAD}{ }^{+}$at $37^{\circ} \mathrm{C}$. Indicated $\mathrm{pH}$ values have been measured after the reaction.

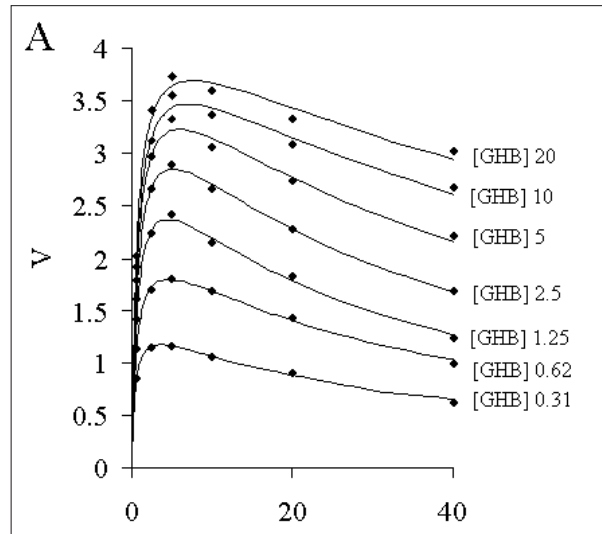

$\left[\mathrm{NAD}^{+}\right]$
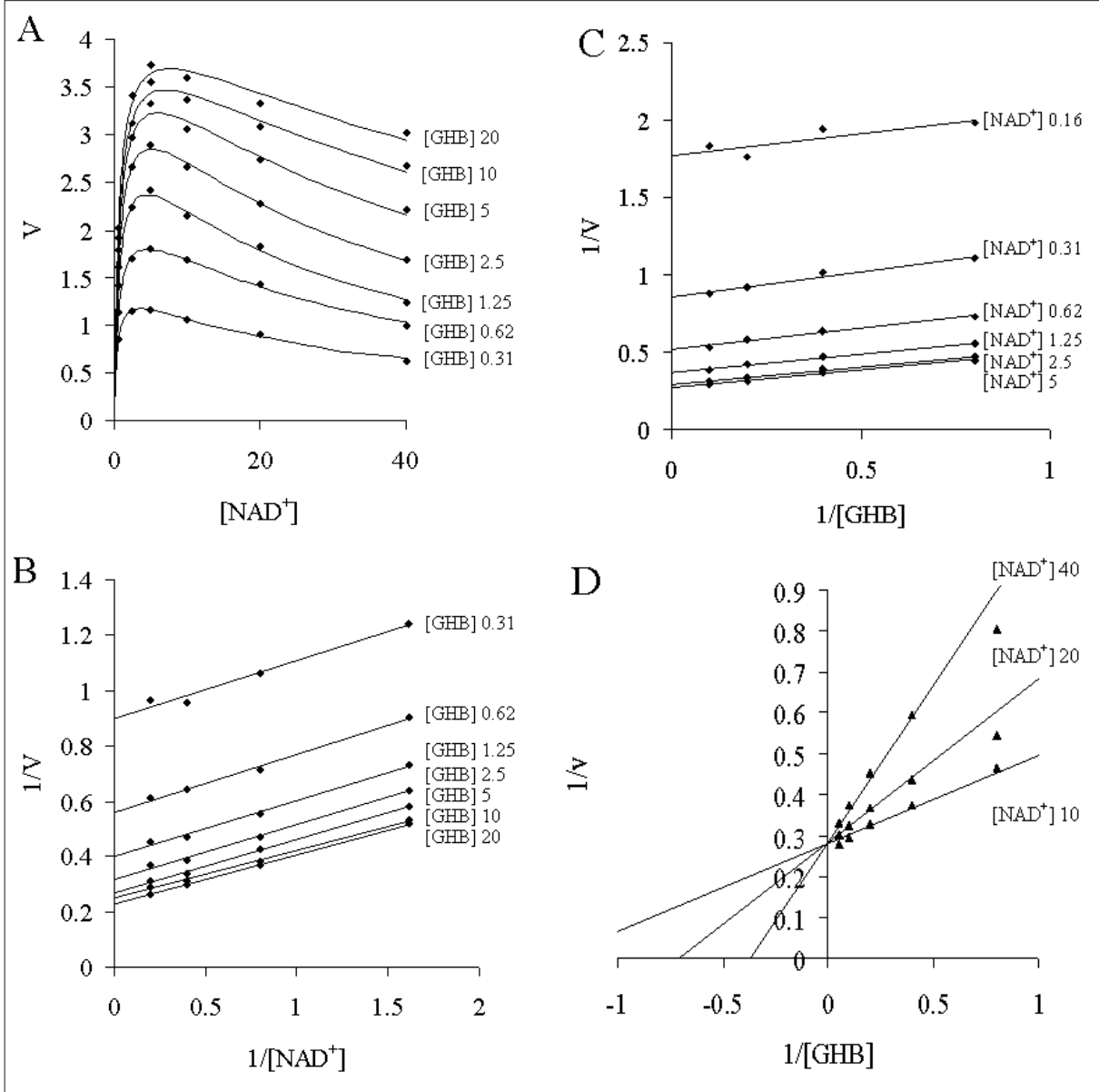

Fig. 3. Measured GHBDH activities are illustrated and depend on the $\mathrm{NAD}^{+}$concentrations at fixed GHB concentrations. The inhibitory effect of $\mathrm{NAD}^{+}$at higher concentrations is clearly shown (A). Double reciprocal representations of these data (dots) and their extrapolated curves for constant GHB (B) and non-inhibiting NAD+ concentrations (C), respectively, yield conserved slopes which fit with the bi bi ping pong mechanism model. ${ }^{[27]}$ The double reciprocal representation at higher $\mathrm{NAD}^{+}$concentrations (D) shows that $\mathrm{NAD}^{+}$acts as a competitive inhibitor conserving a constant $\mathrm{V}_{\max }$. This is consistent with the model of substrate inhibition in the case of a bi bi ping pong mechanism. Dots correspond to the experimental data. Curves in graph $\mathrm{A}$ and $D$ and in graphs $B$ and $C$, respectively, result from shared fits of the data according to the competitive inhibition algorithm and Michaelis-Menten algorithm, respectively. Concentrations of $\mathrm{NAD}^{+}$and $\mathrm{GHB}$, respectively, are given in $\mathrm{mmol} / \mathrm{L}$; initial velocities $(\mathrm{V})$ in $\mathrm{mmol} / \mathrm{min} / \mathrm{mg}$ enzyme.

The optimal activity was predicted by the individual substrate inhibition fits and was reached at a $\mathrm{NAD}^{+}$concentration of $3.7 \mathrm{mmol} / \mathrm{L}$ (estimated from Fig. 3A). At this $\mathrm{NAD}^{+}$concentration, $\mathrm{V}_{\max }$ reached $3.37 \mathrm{mmol} \mathrm{NADH} / \mathrm{min} / \mathrm{mg}$ enzyme and $\mathrm{K}_{\mathrm{M}}$ for $\mathrm{GHB}$ reached $1.0 \mathrm{mmol} / \mathrm{L}$.

The loss in GHBDH activity at NAD ${ }^{+}$ concentrations above $5 \mathrm{mmol} / \mathrm{L}$ consisted in an increase of $\mathrm{K}_{\mathrm{M}}$, while $\mathrm{V}_{\max }$ remained constant (Fig. 3D). Thus, at higher concentrations, NAD ${ }^{+}$behaved like a competitive inhibitor. Consistently with this observation, interpretation of the experimental data with the uncompetitive, non-competitive and competitive algorithms ${ }^{[27]}$ yielded the best match for the competitive inhibition model $\left(\mathrm{R}^{2}=0.98\right)$. A K $\mathrm{i}_{\text {(NAD+ }}$ of $73 \mathrm{mmol} / \mathrm{L}$ was concluded from these data.

Lineweaver-Burke representation of varying (non-inhibiting) $\mathrm{NAD}^{+}$concentrations at fixed GHB concentration and vary- ing GHB concentrations at fixed $\mathrm{NAD}^{+}$ concentration, respectively, showed a conservation of the slopes among the curves (Figs. 3B and 3C). No substrate inhibition was detected in the case of GHB.

\section{Inhibition of GHBDH Activity by Products SSA and NADH}

In the product inhibition experiments, either SSA or NADH was added in varying concentrations to the reaction before the addition of the GHBDH enzyme. SSA was tested at two fixed concentrations, 2 and 10 $\mathrm{mmol} / \mathrm{L}$, and inhibited GHBDH activity. Curves fitted with $\mathrm{R}^{2}>0.99$ according to the non-competitive inhibition model with a $\mathrm{K}_{\mathrm{i} \text { (SSA) }}$ of $8.0 \mathrm{mmol} / \mathrm{L}$ (Fig. 4).

We tested $0.125,0.25,0.5$ and 1 $\mathrm{mmol} / \mathrm{L} \mathrm{NADH}$ for product inhibition using the same conditions as for SSA. Best fit was obtained with the non-competitive inhibition algorithm, yielding a $\mathrm{R}^{2}$ of 0.99 


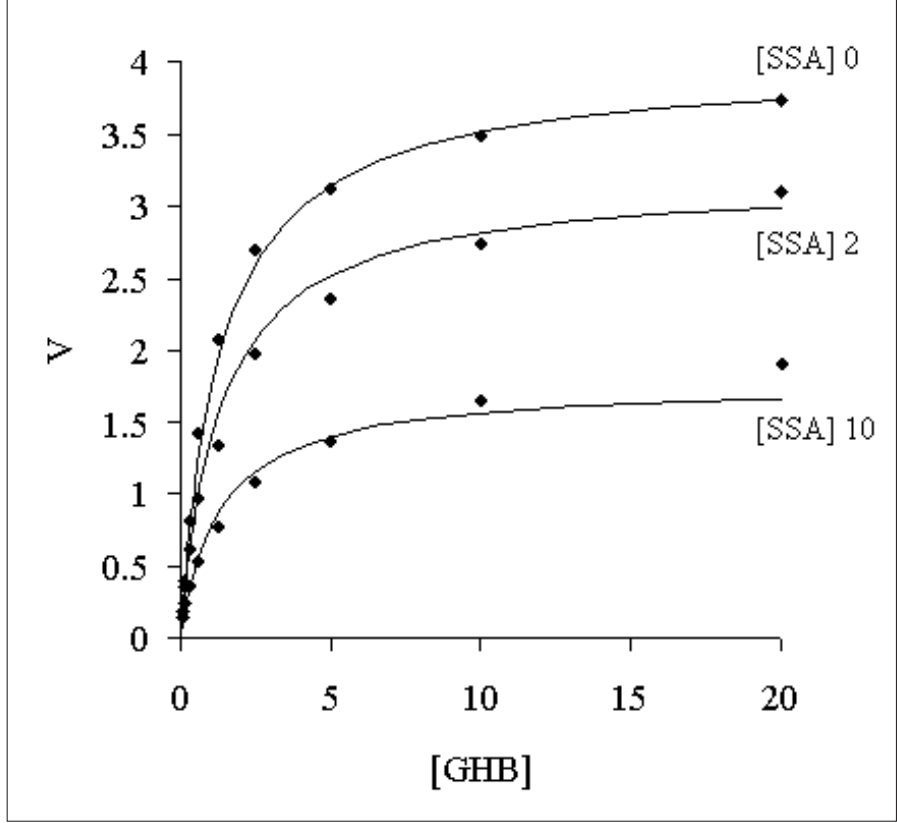

Fig. 4. Michaelis-Menten plots of GHBDH initial velocity dependence on the GHB concentration in the presence of various SSA concentrations. The curves correspond to non-linear regressions calculated according to the non-competitive inhibition algorithm. Reactions were performed using $2 \mu \mathrm{g} \mathrm{GHBDH}$ in the presence of 5 $\mathrm{mmol} / \mathrm{L} \mathrm{NAD}{ }^{+}$. Concentrations of GHB and SSA, respectively, are given in $\mathrm{mmol} / \mathrm{L}$; initial velocities $(\mathrm{V})$ in $\mathrm{mmol} / \mathrm{min} / \mathrm{mg}$ enzyme.

and $\mathrm{K}_{\mathrm{i}(\mathrm{NADH})}$ of $1.74 \mathrm{mmol} / \mathrm{L}$ (experimental data not shown).
Table 1. Recovery of GHB in spiked serum and urine samples from healthy volunteers. The samples were supplemented with $5 \%(\mathrm{v} / \mathrm{v})$ of $\mathrm{GHB}$ solutions containing the corresponding GHB concentrations and assayed according to the protocol described in the Material and Methods section. The recovery (O/E) was calculated by dividing the measured (observed, O) GHB concentration by the expected (endogenous plus added, E) GHB concentration. The percentage recovery was calculated by multiplying O/E by 100 . The data presented are the means of three assay runs for each data point.

$\begin{array}{lcccc}\text { Sample } & \begin{array}{c}\text { GHB added } \\ {[\mu \mathrm{mol} / \mathrm{L}]}\end{array} & \begin{array}{c}\text { Observed } \\ {[\mu \mathrm{mol} / \mathrm{L}]}\end{array} & \begin{array}{c}\text { Expected } \\ {[\mu \mathrm{mol} / \mathrm{L}]}\end{array} & \begin{array}{c}\text { O/E } \\ {[\%]}\end{array} \\ \text { Urine } 1 & 0 & 12 & & \\ & 100 & 119 & 112 & \mathbf{1 0 7} \\ & 500 & 496 & 512 & \mathbf{9 7} \\ \text { Urine 2 } & 800 & 727 & 812 & \mathbf{9 0} \\ & 0 & 19 & & \\ & 100 & 130 & 119 & \mathbf{1 0 9} \\ & 500 & 533 & 519 & \mathbf{1 0 3} \\ \text { Urine 3 } & 800 & 784 & 819 & \mathbf{9 6} \\ & 0 & 21 & & \\ & 100 & 101 & 121 & \mathbf{8 4} \\ & 500 & 397 & 521 & \mathbf{7 6} \\ \text { Serum 1 } & 800 & 570 & 821 & \mathbf{6 9} \\ & 0 & 10 & & \\ & 100 & 142 & 110 & \mathbf{1 2 9} \\ & 500 & 614 & 510 & \mathbf{1 2 0} \\ \text { Serum 2 } & 800 & 905 & 810 & \mathbf{1 1 2} \\ & 0 & 22 & & \\ & 100 & 150 & 122 & \mathbf{1 2 3} \\ & 500 & 607 & 522 & \mathbf{1 1 6} \\ & 800 & 896 & 822 & \mathbf{1 0 9} \\ \text { Serum 3 } & 0 & 0 & & \\ & 100 & 107 & 100 & \mathbf{1 0 7} \\ & 500 & 556 & 500 & \mathbf{1 1 1} \\ & 800 & 814 & 800 & \mathbf{1 0 2}\end{array}$

\section{GHB Standard Curve and Determi- nation of GHB Concentrations in Biological Samples}

For the adaptation of the enzymatic assay from a generic microplate format on the Cobas Mira Plus analyzer, the condi- tions were empirically adjusted for measurement intervals, volumes, $\mathrm{NAD}^{+}$and enzyme concentrations as described in the Material and Methods section. Oxaloacetate and EDTA were added at fixed

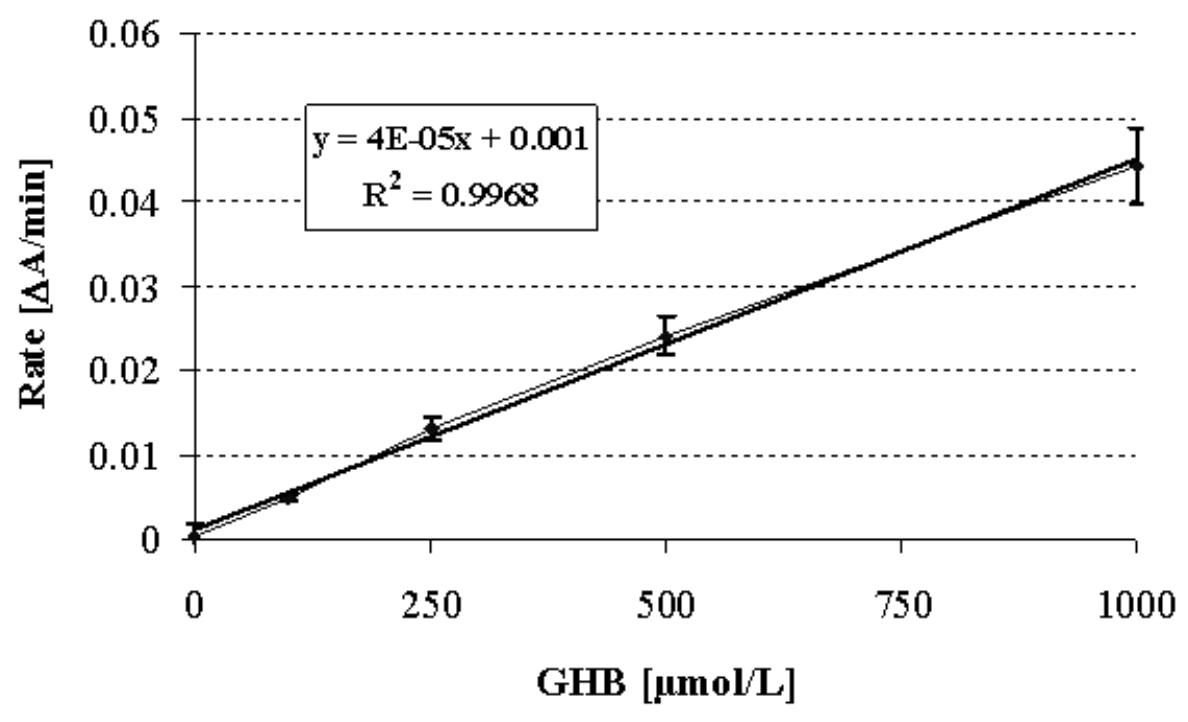

Fig. 5. Representative standard curve. The standard curve was generated by measuring 0 , $100,250,500$ and $1000 \mathrm{umol} / \mathrm{L}$ of GHB dissolved in deionized water in the Cobas Mira Plus instrument. The standard curve shown is the averaged curve plot from seven different assay runs. The error bars represent \pm 1 standard deviation (SD) from the mean values of the corresponding calibration points. concentrations to minimize GHBDH independent conversion of $\mathrm{NAD}^{+}$to $\mathrm{NADH}$ by other enzymes or interfering factors potentially present in biological samples (e.g. lactate dehydrogenase in serum). Sample volumes were established at $10 \%$ of the total reaction volume, for instance $25 \mu \mathrm{L}$ of sample in $225 \mu \mathrm{L}$ of reaction mixture. The GHB calibration curves were generated in deionized water and yielded approximately $0.045 \mathrm{AU}_{340 \mathrm{~nm}}(\Delta \mathrm{A})$ per $\mathrm{mmol} / \mathrm{L} \mathrm{GHB}$ and minute (Fig. 5). This result was close to the kinetic calibration curve data found in microplate assays (data not shown). The GHB in urine and serum, respectively, was deduced from such a standard curve measured in the same assay run as the samples with unknown concentrations.

\section{Spiking Recovery}

Five out of six serum and urine samples from healthy volunteers yielded activities significantly above the calibration blank (zero calibrator) prior to spiking (Table 1). These activities were shown to be GHBDH dependent and were assumed to result from the conversion of endogenous GHB present in the samples. The spiking of these samples with exogenous GHB resulted in observed signal increases $(\Delta \mathrm{A})$ correlating well with expected values. The mean recovery in serum was $114 \%$ with a recovery 


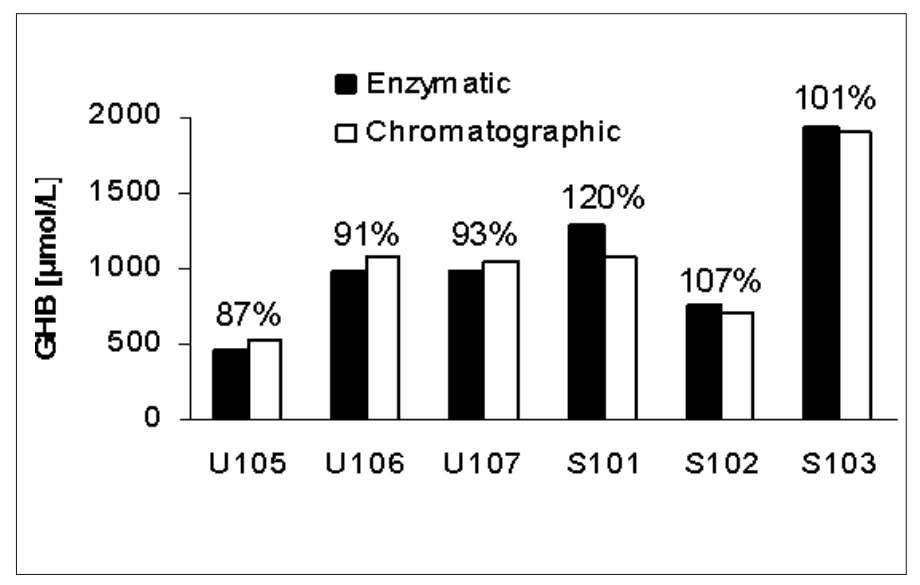

Fig. 6. Method comparison. GHB concentrations were determined in three urine (U105 to U107) and three serum samples (S101 to S103) from overdosed patients using the GHBDH dependent enzymatic assay (dark bars) and compared with the values measured by the ion chromatographic (IC) reference method (open bars). The percentages correspond to the recoveries in GHB concentrations found by our new enzymatic test as compared to IC.

range from 102 to $129 \%$. The mean recovery in urine was $92 \%$ with a recovery range from 69 to $109 \%$.

\section{Method Comparison}

Three urine and serum samples each from overdosed patients with GHB concentrations above $0.2 \mathrm{mmol} / \mathrm{L}$ were tested in parallel with the GHBDH dependent enzymatic assay and the ion chromatographic (IC) method. The means differences were $10 \%$ for urine and $9 \%$ for serum, respectively (Fig. 6). The urine samples exhibited slightly lower GHB concentrations with our new enzymatic method, while serum samples tended to be higher than the levels measured by the IC method.

\section{Discussion}

The aim of this study was the development and characterization of an easy and rapid test method to determine GHB in biological fluids. To achieve this ambitious goal, we decided to create an enzymatic test procedure based on a recombinant enzyme, the GHB dehydrogenase (GHBDH, EC 1.1.1.61). As this enzyme was commercially not available, we synthesized the enzyme using the sequence from the Ralstonia eutropha gdb gene and expressed it as a fusion protein in E. coli. Thus, the first step of this work was the characterization of the recombinant GHBDH.

In mammalian brain, GHB is formed primarily by the transamination of GABA and then oxidized to succinic semialdehyde (SSA) by GHBDH using $\mathrm{NAD}^{+}$. SSA is further oxidized to succinic acid that enters the Krebs cycle. [1] However, SSA is also reduced 'back' to GHB by the succinic semialdehyde reductase (EC 1.1.1.2) using $\mathrm{NAD}(\mathrm{P}) \mathrm{H}$. SSA reductase and GHBDH catalyze basically the same reactions in opposite directions. Previous studies on bacterial GHBDHs have shown that the reaction in the sense of oxidization of GHB to SSA is not favored and that the 'reverse reaction' was enzyme-kinetically more favorable. ${ }^{[22,28]}$ This has been confirmed in this work. Consequently, we had to stress and optimize the oxidization of GHB to SSA.

First, $\mathrm{pH}$ screening was performed in PBS and Tris-HCl. The $\mathrm{pH}$ optimum for GHBDH activity was found to be reached between $\mathrm{pH} 9.5$ and 10. Consequently, in our application, reactions were performed at $\mathrm{pH} 10.0$ in the presence of $270 \mathrm{mM}$ AMPD. This buffer has an alkaline $\mathrm{pKa}$ of 8.8 and contributed to a markedly higher activity than Tris- $\mathrm{HCl}$ at the same $\mathrm{pH}$.

The reaction mechanism of GHBDH has not been characterized so far. GHBDH catalyzes a multi-substrate reaction, where GHB oxidation to SSA implicates the reduction of $\mathrm{NAD}^{+}$to NADH. Multi-substrate type enzymes can be divided in two major classes depending on the way the half-reactions are coupled. ${ }^{[27]}$ In enzymes following the sequential model mechanism, the enzyme and the substrates form a ternary complex and both half-reactions occur simultaneously. Other enzymes follow the ping pong mechanism. They do not form ternary complexes with the substrates. Schematically, the substrate to be bound first modifies the enzyme, by the transfer of a chemical group for example, and is released as a first modified product. The modified enzyme is then capable to bind the second substrate and to modify it to a second product. The latter step also regenerates the enzyme to its initial con- figuration. Two typical features, yielded by data processing, argue for GHBDH working according to a bi bi ping pong mechanism. First, double-reciprocal plots of initial velocity against NADH or GHB show typical parallel curves with conserved $\mathrm{K}_{\mathrm{M}} /$ $\mathrm{V}_{\text {max }}$ slopes. Secondly, substrate inhibition by NAD ${ }^{+}$obeys a competitive mode.

In the classical bi bi ping pong model, substrates dock at the same enzyme binding site and compete for its access. However, our product inhibition studies showed non-competitive behaviors of the substrates that do not correspond to the classical bi bi ping pong mode. Divergences to the classical model are generally an indication of a spatial repartition of the two half reactions over different binding sites on the same enzyme molecule. Since substrates dock to separate sites, they do not compete for binding. This has been proposed for $\mathrm{NAD}(\mathrm{P})^{+} / \mathrm{NAD}(\mathrm{P}) \mathrm{H}$ depending dihydropyridine and dihydroorotate dehydrogenases. ${ }^{29]}$ These enzymes are assumed to follow a non classical bi bi ping pong mechanism and share similarities with GHBDH on behalf of kinetic properties and catalyzed reactions. They contain flavin groups and iron atoms that are supposed to feature an electron transport chain connecting the two distinct sites where the half-reactions occur. ${ }^{[29]}$ GHBDH structure has not been investigated yet. Nevertheless, GHBDH of Clostridium kluyveri has been shown to contain two atoms of copper and one atom of iron which could potentially be involved in an electron transfer reaction. ${ }^{[28]}$ In our application, GHB is the varying substrate. Therefore, we determined the optimal $\mathrm{NAD}^{+}$concentration for the assay and fixed it. Actually, according to reaction mechanism, the $\mathrm{NAD}^{+}$concentration does not influence the slope $\mathrm{K}_{\mathrm{M}} / \mathrm{V}_{\text {max }}$ and, consequently, the analytical sensitivity of the test. It is expected that even substantial variations in $\mathrm{NAD}^{+}$concentration will not affect measurements in the linear range. However, these variations may affect the limits of the linear range itself, which depends on $\mathrm{K}_{\mathrm{M}(\mathrm{GHB})}$ and is, therefore, directly influenced by the $\mathrm{NAD}^{+}$concentration. For an application in which samples of overdosed patients should be determined, it appeared relevant to seek the extension of the linear range towards high GHB concentrations by maximizing $\mathrm{NAD}^{+}$and, consequently, $\mathrm{K}_{\mathrm{M}(\mathrm{GHB})}$. For a $\mathrm{NAD}^{+}$concentration of $5 \mathrm{mmol} / \mathrm{L}, \mathrm{K}_{\mathrm{M}(\mathrm{GHB})}$ reaches $1.0 \mathrm{mmol} / \mathrm{L}$, which predicts an acceptable linearity up to an effective concentration of at least $1 \mathrm{mmol} / \mathrm{L} \mathrm{GHB}$ in reaction. GHB levels above this value can be detected qualitatively, but such overdosed samples should be further diluted for accurate quantification if necessary.

Apart from the extensive physicochemical characterization of this new 
enzymatic assay, we have also tested its performance in measuring GHB in human blood and urine samples. Recovery data of GHB-spiked samples from healthy individuals as well as comparisons of overdosed samples to an ion chromatographic reference method revealed that this enzymatic assay can be used as a simple, rapid and accurate alternative to the existing, labor and time consuming chromatographic methods. Based on the few results from a total of twelve patient samples only, GHB levels in urine may be slightly underestimated by this new method, whereas serum levels may be somewhat overestimated, most probably due to matrix interferences. Further experiments must be done to optimize the assay procedure and its performance in order to eliminate such matrix interferences among other fine tuning steps. Secondly, more biological samples from healthy volunteers as well as from intoxicated patients must be investigated in a clinical follow-up study. The GHBDH dependent enzymatic assay presented in this work will be made commercially available after the latter validation steps.

\section{Acknowledgements}

This work was supported by a grant 7813.2 from the Commission for Technology and Innovation of the Swiss Federal Office for Education and Technology.

Received: September 6, 2010
[1] M. Maitre, Prog. Neurobiol. 1997, 51, 337.

[2] O. C. Snead 3rd, K. M. Gibson, N. Engl. J. Med. 2005, 352, 2721.

[3] M. Pistis, A. L. Muntoni, G. Pillolla, S. Perra, G. Cignarella, M. Melis, G. L. Gessa, Neuroscience 2005, 131, 465.

[4] J. Suhl, J. Pharm. Pract. 2007, 20, 181.

[5] F. Caputo, S. Francini, M. Stoppo, F. Lorenzini, T. Vignoli, A. Del Re, C. Comaschi, L. Leggio, G. Addolorato, G. Zoli, M. Bernardi, J. Psychopharmacol. 2009, 23, 883.

[6] C. Hopfer, B. Mendelson, J. M. Van Leeuwen, S. Kelly, S. Hooks, Am. J. Addict. 2006, 15, 94.

[7] L. Degenhardt, J. Copeland, P. Dillon, Subst. Use Misuse 2005, 40, 1241.

[8] A. Negrusz, R. E. Gaensslen, Anal. Bioanal. Chem. 2003, 376, 1192.

[9] J. Li, S. A. Stokes, A. Woeckener, Ann. Emerg. Med. 1998, 31, 729.

[10] P. E. Mason, W. P. Kerns 2nd, Acad. Emerg. Med. 2002, 9, 730.

[11] A. F. Tarabar, L. S. Nelson, Toxicol. Rev. 2004, 23, 45.

[12] M. McDonough, N. Kennedy, A. Glasper, J. Bearn, Drug Alcohol Depend. 2004, 75, 3.

[13] R. Brenneisen, M. A. Elsohly, T. P. Murphy, J. Passarelli, S. Russmann, S. J. Salamone, D. E. Watson, J. Anal. Toxicol. 2004, 28, 625

[14] C. Haller, D. Thai, P. Jacob 3rd, J. E. Dyer, J. Anal. Toxicol. 2006, 30, 360.

[15] M. A. LeBeau, M. A. Montgomery, C. MorrisKukoski, J. E. Schaff, A. Deakin, Forensic Sci. Int. 2007, 169, 152.

[16] G. De Paoli, S. Bell, J. Anal. Toxicol. 2008, 32, 298.

[17] R. Paul, L. Tsanaclis, R. Kingston, A. Berry, A. Guwy, J. Anal. Toxicol. 2006, 30, 375.

[18] D. Richard, B. Ling, N. Authier, T. W. Faict, A. Eschalier, F. Coudoré, Anal. Chem. 2005, 77, 1354.

[19] J. E. Meyers, J. R. Almirall, J. Forensic Sci. 2005, 50, 31 .
[20] S. Elliott, V. Burgess, Forensic Sci. Int. 2005 , 151, 289.

[21] W. C. Alston 2nd, K. Ng, Forensic Sci. Int. 2002, 126,114

[22] D. T. Bravo, D. O. Harris, S. M. Parsons, J. Forensic Sci. 2004, 49, 379.

[23] U. K. Laemmli, Nature 1970, 227, 680.

[24] M. Bradford, Anal. Biochem. 1976, 72, 248.

[25] M. Jordi, A. Scholer, J. Gonzales, Poster at the IATDMCT congress, Basel 2003.

[26] M. Jordi, Diploma thesis, Fachhochschule Nordwestschweiz (FHNW), 2002/3, Muttenz, Switzerland.

[27] W. W. Cleland, Biochim. Biophys. Acta. 1963, 67, 104.

[28] R. A. Wolff, W. R. Kenealy, Protein Expr. Purif. 1995, 6, 206.

[29] B. Podschun, P. F. Cook, K. D. Schnackerz, J. Biol. Chem. 1990, 265, 12966. 